\title{
Numerical simulation of the mold filling process and its experimental validation
}

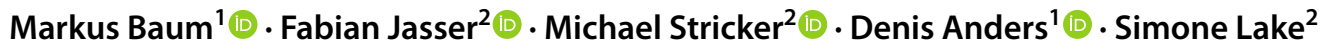

Received: 10 November 2021 / Accepted: 4 February 2022 / Published online: 1 March 2022

(c) The Author(s) 2022

\begin{abstract}
The present study deals with the simulation of the filling process in injection molding using Ansys CFX and its experimental validation. For this purpose, the filling process of an exemplary mold is investigated numerically as well as experimentally at different time steps. For the numerical investigation, a suitable model is elaborated in Ansys CFX, which enables such a comparison. In particular, the representation of a suitable viscosity model for polymers is not common in Ansys CFX. Therefore, the Carreau-WLF viscosity model is adapted for the considered polymer Schulamind 66 SK 1000 and integrated into Ansys CFX. The contribution focuses on the comparison of the numerically calculated flow front contour and the respective filling levels of the melt from experiments. Furthermore, a detailed numerical analysis of temperature and viscosity profiles is included in order to illustrate the effect of shear-induced temperature changes and the interplay between the temperature field and the viscosity of the injected polymer. In conclusion, the numerical model nicely fits the experimental results despite some slight deviations in the early filling stages.
\end{abstract}

Keywords Injection Molding $\cdot$ Computational Fluid Dynamics $\cdot$ Mold filling $\cdot$ Polymer $\cdot$ Carreau-WLF

\section{Introduction}

The injection molding process is one of the most frequently used manufacturing processes for plastic components [1]. During the last few decades, the injection molding process and its computer-based prediction has been continuously improved. This includes the development of numerical simulation models, which should enable a preliminary part and mold design without experiments. Nowadays, the two-dimensional (2D) simulation models are the most frequently used approaches to simulate the filling stage due to their low computational cost compared to fully coupled $3 \mathrm{D}$ approaches $[2,3]$. These are based on the Hele-Shaw formulation [4]. There are two different approaches for the computational analysis of $2 \mathrm{D}$ flows. The first approach is

Markus Baum

markus.baum@th-koeln.de

1 Group for Computational Mechanics and Fluid Dynamics, Cologne University of Applied Sciences (TH Köln), Steinmüllerallee 1, 51643 Gummersbach, Germany

2 Group for Polymer Processing, Cologne University of Applied Sciences (TH Köln), Steinmüllerallee 1, 51643 Gummersbach, Germany developed by Tadmor et al. [5] and is called network-flow. In this approach the cavity is discretized by a network of rectangular elements. The velocity field of the flow front is used to calculate the melt flow. Hieber and Shen [6] developed a two-stage predictor-corrector method. Their method works in a very similar way like the first approach. New finite elements are constantly created on the evolving flow front by tracking methods. The respective existing velocities and the current geometry are taken into account for the spatial discretization. Wang et al. [7] examined the flow of the melt in thin-walled cavities with a 3D configuration. This configuration consists of the hybrid application of the finite element method (FEM) and the finite difference method (FDM) with a control volume. The sprue, the distribution channels, and the cavity are discretized as a network of $1 \mathrm{D}$ pipe elements and triangular 2D shell elements. The melt is automatically distributed by calculating the volume fraction filled in and the subsequent assignment of the control volume. This approach is expanded in various commercial software applications (e.g., Moldex 3D, Moldflow, Cadmould 3D-F, and Simpoe) as well as in research. These stages include the holding pressure stage [2, 8-10], mold cooling [11], fiber orientation [7, 12-15] as well as shrinkage and warpage [16-18]. However, this framework only 
applies to thin-walled and less complex structures [19-28]. Therefore, numerical approximations that represent a 3D flow of the mold filling are required for the simulation of these molded parts. Numerical 3D simulation programs, such as Ansys CFX, can represent these complex flow scenarios very accurately.

Optimizing product quality requires a high level of simulation accuracy and a deep understanding of the process [29]. However, before the influence of the process variables can be determined, a reliable and accurate simulation model must exist. Only then, the interaction between the process variables, such as volume flow, temperature, and process pressure, can be assessed. The assessment is based on typical quality features such as cycle time, shrinkage, and warpage. These simulation results can be used for iterative optimization, e.g., through the application of artificial neural networks, genetic algorithms, or machine learning techniques [30-33].

\section{Basic description of the injection molding process}

In general, the numerical simulation of mold filling processes and their experimental validation require a basic understanding of the injection molding process. The structure of an injection molding machine with the most fundamental functional units is shown in Fig. 1. The so-called plasticizing and injection unit is of central importance for the injection molding process. The thermoplastic polymer (granules) is melted, homogenized, and metered up to the required quantity in this unit. The polymer is transported to the nozzle and collected between the nozzle and the screw. The polymer melt is then injected under high pressure into a molding cavity in the injection mold located in the clamping unit. After the cavity has been filled volumetrically (injection stage), the polymer is further compressed, cooled and the volume shrinkage is partly compensated in

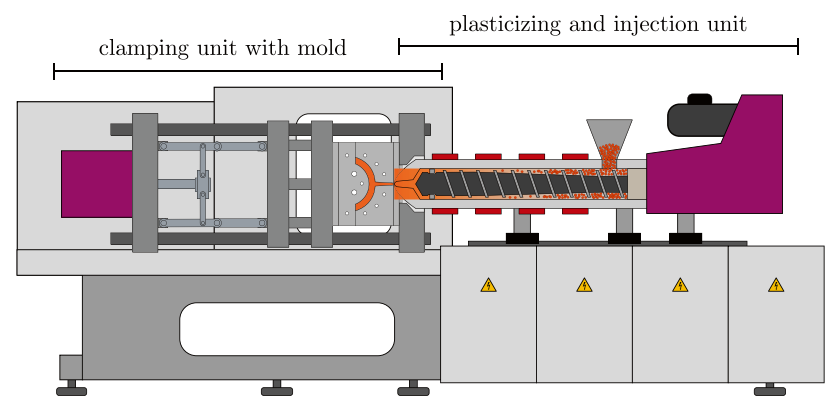

Fig. 1 Illustration of an injection molding machine (sectional view) with the plasticizing and injection unit (right) and the clamping unit with mold (left) the holding pressure stage. As soon as sufficient rigidity has been achieved to allow demolding, the mold is opened, and the injection-molded part is ejected from the mold. This periodically recurring process is called an injection molding cycle. In this process, plastic components are often produced directly ready for use. The main advantages of the injection molding process are the extremely fast, automated, and costeffective production of complex molded parts in large quantities, which usually do not require any post-processing. The main disadvantage is referred to the relatively high manufacturing costs of the injection molding tool for very complex injection geometries. For this reason, subsequent changes to the mold are cost-intensive and should be prevented by thorough numerical investigations in the early stages of product and mold design. To achieve optimum results in the injection molding process, various parameters, part properties, mold design, and material properties have to be coordinated in a purposeful manner. This requires a process-oriented design of the molded part, the optimization of gating systems, and the setting of suitable speed profiles to achieve uniform filling of single and multiple cavities, cf. [34, 35]. The injection molding process is fundamentally subject to considerable inhomogeneities and often involves thermal or rheological transient behavior. For example, different geometric thickness variations in the mold lead to inhomogeneous flow resistances [36]. The boundary layers of the melt solidifying at the cooler mold wall additionally cause a local and timerelated change of the flow cross-sections. Consequently, the flow conditions become transient. The inhomogeneous filling conditions result from different flow velocities as well as shear stresses within the cavity and influence part properties, among other things, with regard to orientations of molecular chains as well as fillers. This can eventually cause significant geometric deformations (shrinkage and warpage) in the molded part, which are considered typical processing defects. Other phenomena that can be analyzed using injection molding simulation are weld lines, air traps, sink marks, surface defects, shrinkage voids, and burning (diesel effect) [35]. A balanced filling process, especially for complex geometries, and multiple cavities, is a very challenging task. For this purpose, numerical filling studies should be used in the early stages of product development and mold design to identify and eliminate design problems, if necessary. In the subsequent mold validation process, a filling study carried out in small steps allows the filling behavior of the injection mold to be mapped under real conditions and referenced with the simulations carried out in advance. In this way, for example, manufacturing inaccuracies that are not taken into account in the simulation can be corrected [35]. The characteristics of mold filling thus have a significant influence on the subsequent product quality. Therefore, the focus of this article will be on the injection stage in the mold. 


\section{Numerical modelling of the mold filling}

\subsection{Presentation of the test scenario}

In the scope of this contribution, the authors focus on the filling phase of an exemplary specimen. Within the testing scenario, liquid polymer melt fills the given cavity through a pre-defined sprue. During the filling process, the contained air is displaced by the melt. This actually involves a twophase free surface flow. For the numerical modelling, it is crucial to capture the time-dependent velocity and pressure fields during filling subjected to the complex rheological properties of the polymer as well as the high compressibility of the entrained air. Figure 2 illustrates the geometrical configuration of the considered specimen.

\subsection{Governing equations}

A fully volumetric approach is used for the filling phase. This is based on the three-dimensional spatial discretization of the cavity. The cavity volume as well as the governing Navier-Stokes equations are discretized by means of the finite volume method (FVM). The FVM is the established standard discretization scheme for Computational Fluid Dynamics [29, 37, 38]. During the filling phase, the flow of the melt can be assumed to be incompressible [37] and, due to the relatively short process duration, isothermal [27]. In Ansys CFX, the filling of the cavity can be described by a homogeneous multiphase model or an inhomogeneous model. The homogeneous model assumes that both phases are transported in the same proportion. In the homogeneous model, the phases share the same flow fields for, for example, the velocity and the temperatures. With this assumption,

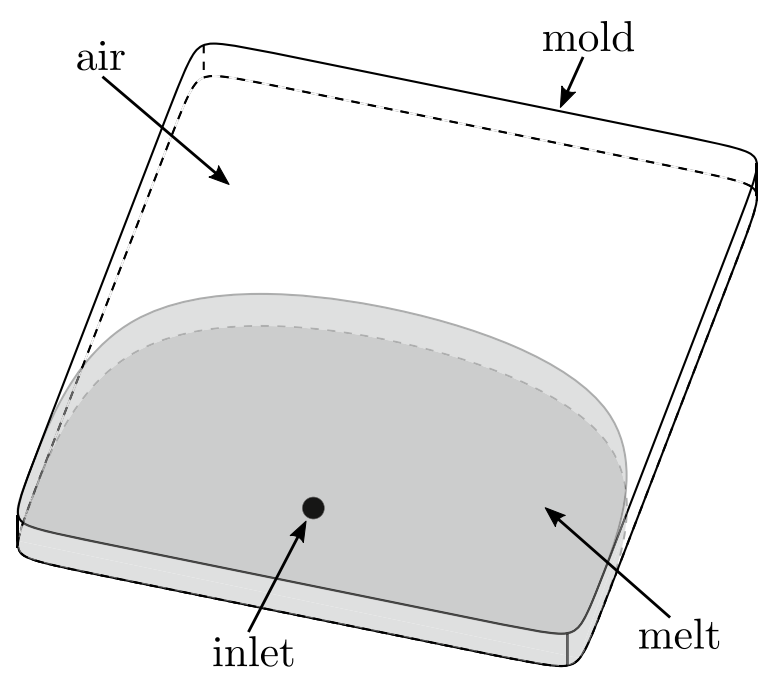

Fig. 2 Model of the test scenario the transport equation can be combined. Igreja's work [39] shows that the homogeneous model does not give correct results. This model uses the same boundary conditions for both fluids. Haagh et al. [40, 41] suggest the use of no-slip boundary conditions for the first phase (melt). Mukras and Al-Mufadi [37] Ansys CFX depicts this as an inhomogeneous model. Since every phase in this model has its own flow field, the free-slip boundary condition can additionally be used for the second phase (air) [37]. The interaction of the phases takes place via interphase transfer terms [39].

In the following equations $\alpha$ (melt) and $\beta$ (air) represent the two phases. According to this model, the mass balance equation for each phase can be described by [37, 39, 42]:

$\frac{\partial}{\partial t}\left(r_{\alpha} \rho_{\alpha}\right)=\nabla\left(r_{\alpha} \rho_{\alpha} \mathbf{U}_{\alpha}\right)$

$\frac{\partial}{\partial t}\left(r_{\beta} \rho_{\beta}\right)=\nabla\left(r_{\beta} \rho_{\beta} \mathbf{U}_{\beta}\right)$

This equation includes the density $\rho$, the velocity vector $\mathbf{U}$, the time $t$ and the volume fraction $r$. The momentum balance for each phase can be described by the following equation $[37,39,42]$ :

$$
\begin{aligned}
\frac{\partial}{\partial t}\left(r_{\alpha} \rho_{\alpha} \mathbf{U}_{\alpha}\right) & +\nabla\left(r_{\alpha} \rho_{\alpha} \mathbf{U}_{\alpha} \otimes \mathbf{U}_{\alpha}\right)=-r_{\alpha} \nabla p \\
& +\nabla\left[r_{\alpha} \mu_{\alpha}\left(\nabla \otimes \mathbf{U}_{\alpha}+\left(\nabla \otimes \mathbf{U}_{\alpha}\right)^{T}\right)\right] \\
& +\mathbf{S}_{\mathbf{M} \alpha}+\mathbf{M}_{\alpha \beta} \\
\frac{\partial}{\partial t}\left(r_{\beta} \rho_{\beta} \mathbf{U}_{\beta}\right) & +\nabla\left(r_{\beta} \rho_{\beta} \mathbf{U}_{\beta} \otimes \mathbf{U}_{\beta}\right)=-r_{\beta} \nabla p \\
& +\nabla\left[r_{\beta} \mu_{\beta}\left(\nabla \otimes \mathbf{U}_{\beta}+\left(\nabla \otimes \mathbf{U}_{\beta}\right)^{T}\right)\right] \\
& +\mathbf{S}_{\mathbf{M} \beta}+\mathbf{M}_{\beta \alpha}
\end{aligned}
$$

The equations are subjected to the condition that the two phases completely fill the volume of the cavity. This condition is expressed as $[37,39]$ :

$r_{\alpha}+r_{\beta}=1$

For each phase, the terms $\mathbf{S}_{\mathbf{M} \alpha}$ and $\mathbf{S}_{\mathbf{M} \beta}$ are related to the momentum caused by the gravitational force and are given by [37, 39]:

$\mathbf{S}_{\mathbf{M}} \alpha=r_{\alpha}\left(\rho_{\alpha}-\rho_{\text {reference }}\right) \mathbf{g}$

$\mathbf{S}_{\mathbf{M}} \beta=r_{\beta}\left(\rho_{\beta}-\rho_{\text {reference }}\right) \mathbf{g}$

The momentum balances contain an interface that shows the interaction between the phases per unit volume, cf. [37]. These are described by the interphase momentum transfer 
terms $\mathbf{M}_{\boldsymbol{\alpha} \boldsymbol{\beta}}$ and $\mathbf{M}_{\boldsymbol{\beta} \boldsymbol{\alpha}}$ [39]. Their relationship is defined as follows [37, 39]:

$\mathbf{M}_{\alpha \beta}=-\mathbf{M}_{\beta \alpha}$

According to Igreja and Frank [39, 42], the interphase momentum transfer term $\mathbf{M}_{\alpha \beta}$ can be described by:

$\mathbf{M}_{\alpha \beta}=\frac{C_{D} r_{\alpha} r_{\beta}}{d_{\alpha \beta}}\left(\rho_{\alpha} r_{\alpha}+\rho_{\beta} r_{\beta}\right)\left|\mathbf{U}_{\beta}-\mathbf{U}_{\alpha}\right|\left(\mathbf{U}_{\beta}-\mathbf{U}_{\alpha}\right)$

Here $C_{D}$ is the drag coefficient and $d_{\alpha \beta}$ is the interface length scale.

The rheological properties are used to describe the viscosity of a material. The fluid viscosity $\eta$ of a polymer melt is strongly dependent on the shear rate, temperature, and pressure. Thermoplastic polymers show typical pseudoplastic behavior at a high shear rate. To approximate the entire viscosity curve of a thermoplastic, the Carreau approach [43] is used with a constant temperature curve [44, 45].

$\eta(\dot{\gamma})=\frac{P_{1}}{\left(1+\dot{\gamma} P_{2}\right)^{P_{3}}}$

The coefficient $P_{1}$ describes the zero viscosity, $P_{2}$ the transition area between the Newtonian and structurally viscous flow behavior, and $P_{3}$ the function's gradient in the structurally viscous area. These coefficients are positive, and $P_{3}$ is less than 1. [44]

The temperature shift describes the thermal behavior of the fluid viscosity according to William-Landel-Ferry (WLF) [46]. The coefficients of the reference temperature $T_{S}$, the material-specific reference temperature $T_{0}$, and the material temperature $T$ can be summarized in Eq. 11 by the temperature shift factor $\alpha_{T}$ [47]. The constants $C_{1}$ and $C_{2}$ are dependent on the polymer and the reference temperature [48].

$\log _{10} \alpha_{T}=\frac{C_{1}\left(T_{0}-T_{S}\right)}{C_{2}+\left(T_{0}-T_{S}\right)}-\frac{C_{1}\left(T-T_{S}\right)}{C_{2}+\left(T-T_{S}\right)}$

Measurements on different polymers show that the constants $C_{1}$ and $C_{2}$ are identical for almost all polymers as long as the glass transition temperature is used as the reference temperature [49]. The approach employed for the constants $C_{1}=8.86$ and $C_{2}=101.6[50,51]$.

Taking into account the fluid viscosity and the temperature influence in the form of the temperature shift factor, the equation is obtained as the Carreau-WLF model [47].

$\eta(\dot{\gamma}, T, p)=\frac{P_{1} \alpha_{T}}{\left(1+\dot{\gamma} P_{2} \alpha_{T}\right)^{P_{3}}}$

\subsection{Boundary conditions}

The description of the boundary conditions for the test scenario is depicted in Fig. 3. The simulation employed an inhomogeneous multiphase model for the filling process [40]. Based on the research by Mukras and Al-Mufadi [37], the following boundary conditions are used to reproduce the real process properties of the mold filling during injection molding. Two different kinds of boundary conditions are used on the cavity walls. A no-slip boundary condition with the velocity vector $\mathbf{U}=\mathbf{0}$ is used on the cavity wall only for the melt $A_{\text {wall,melt }}$. The boundary condition for air at the wall $A_{\text {wall,air }}$ is specified as a free slip condition $\mathrm{T} \cdot \mathbf{n}=\mathbf{0}$. T represents the stress tensor and $\mathbf{n}$ the unit vector in the normal direction. The inlet surface $A_{\text {inlet }}$ is specified with a constant mass flow rate of the melt $\dot{m}_{\text {melt }}$. To optimize the calculation time, a halved geometry with a plane of symmetry was used, cf. Fig. 4. In addition, all variables are used with the initial boundary conditions or with the reasonable values [37].

\subsection{Discretization}

In the test scenarios, the same geometry is used for both the simulation and the experiments, cf. Fig. 5. The simulation of the mold filling is set up and realized in Ansys CFX. The melt is considered as a viscous fluid and the flow is non-Newtonian, isothermal, and incompressible. To describe the non-Newtonian flow behavior, the Carreau and Carreau-WLF are employed. Based on the studies of Baum and Anders [52], the parameters for the viscosity models of the polymer Schulamid 66 SK 1000 are shown in Table 1 and the material properties are given in Table 2.

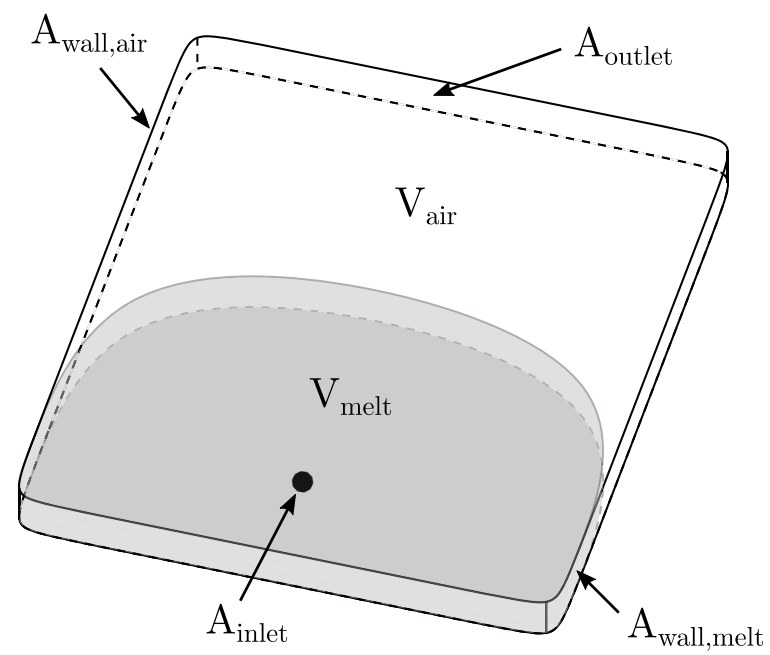

Fig. 3 Description of the boundary conditions in the mold 


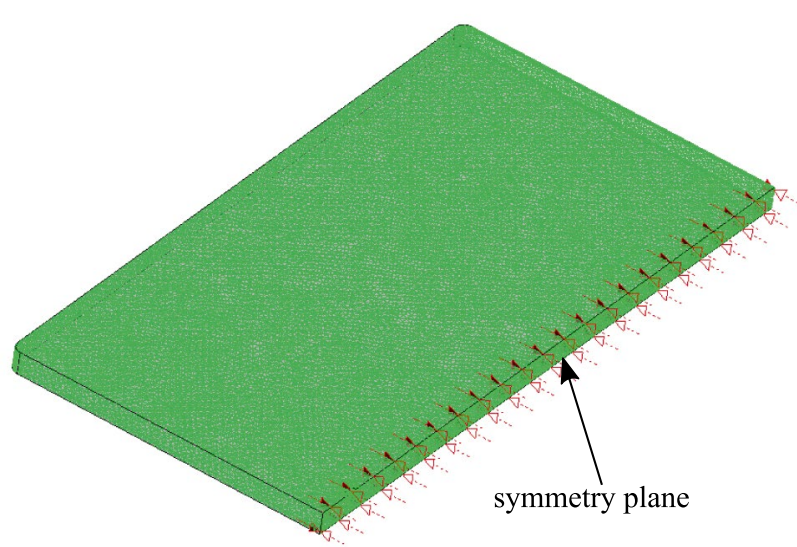

Fig. 4 Mesh in Ansys CFX with the symmetry plane

The inlet was set up with a constant mass flow rate of $\dot{m}_{\text {melt }}=0.015996 \mathrm{~kg} / \mathrm{s}$ for the halved geometry. The halved geometry is realized with a symmetry plane. The static pressure at the outlet is $p_{\text {stat }}=0 \mathrm{bar}$ and was defined as an opening. The inlet was defined with a constant temperature of $T_{\text {inlet }}=280^{\circ} \mathrm{C}$ and the wall is modelled with a constant temperature of $T_{\text {wall }}=80^{\circ} \mathrm{C}$. The CFD simulation in Ansys CFX uses a full volumetric mesh and consisted of pyramids, tetrahedra, and wedges. In total, it is build up with 299115 elements. The mesh is prepared with 5 inflation layers at the walls and a maximum element size of $0.5 \mathrm{~mm}$. The simulation makes use of an adaptive time step control with a maximum time step of $10^{-3} \mathrm{~s}$. For all equations, a residual convergence target of $10^{-5}$ is used with a limit of 50 iterations.

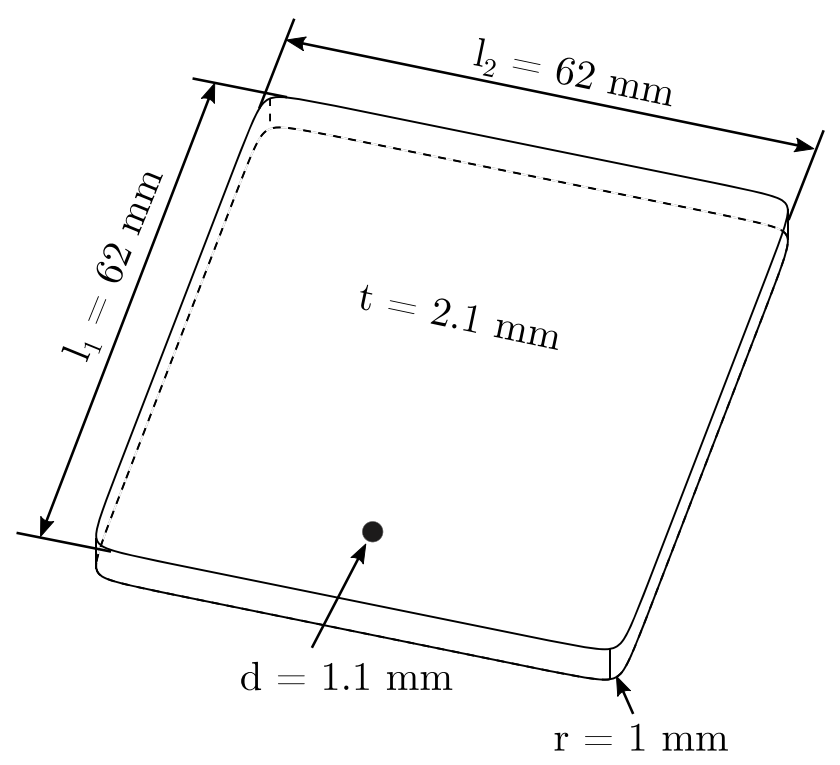

Fig. 5 Description of the dimensions in the considered specimen
Table 1 Carreau and CarreauWLF parameters for Schulamid 66 SK 1000

\begin{tabular}{ll}
\hline Parameter & Value \\
\hline$P_{1}$ & $900.83269 \mathrm{~Pa} \cdot \mathrm{s}$ \\
$P_{2}$ & $0.026588668 \mathrm{~s}$ \\
$P_{3}$ & 0.50322362 \\
$T_{0}$ & $290{ }^{\circ} \mathrm{C}$ \\
$T_{S}$ & $128.72119^{\circ} \mathrm{C}$ \\
$C_{1}$ & 8.86 \\
$C_{2}$ & 101.6 \\
\hline
\end{tabular}

\section{Experimental setup}

The contribution focuses on a thorough investigation of the melt flow within in the injection mold employing different viscosity models. Especially, the tracking of the flow front within a cavity is of great interest. In the experimental setup, a two-cavity mold is used for the production of the specimen. The cavity has a length and width of $62.0 \mathrm{~mm}$ and a thickness of $2.1 \mathrm{~mm}$. The parts meet the geometrical requirements of DIN EN ISO 294 (Campus plate). A tie-bar-less all-electric injection molding machine (Engel EM 200/100) with a screw diameter of $30 \mathrm{~mm}$ and a maximum clamping force of $1000 \mathrm{kN}$ was used. Polyamide 66 (SCHULAMID 66 SK 1000) is the material for the testing procedure. The basic properties of the plastic material are listed in Table 3 .

The simulation results were validated in injection molding tests. Suitable parameters for injection molding are first determined and set. The corresponding setting parameters are shown in Table 4. Subsequently, a filling series was performed without holding pressure. This is done by starting with a metering volume set considerably too low and increasing it from cycle to cycle. The ejected parts then show the progression of the flow front. In this test, eight successive filling levels were conducted. These allow a stepby-step observation and range from the entry of the melt into the cavity to complete filling.

Table 2 Material properties for Schulamid 66 SK 1000 and air used for simulation

\begin{tabular}{lll}
\hline Material & Property & Value \\
\hline Polymer & Density (melt) & $860 \mathrm{~kg} / \mathrm{m}^{3}$ \\
& Density (solid) & $1060 \mathrm{~kg} / \mathrm{m}^{3}$ \\
& Specific heat capacity & $1700 \mathrm{~J} /(\mathrm{kg} \mathrm{K})$ \\
& Thermal conductivity & $0.28 \mathrm{~W} /(\mathrm{m} \mathrm{K})$ \\
& Thermal diffusivity & $0.19 \mathrm{~mm}^{2} / \mathrm{s}$ \\
Air & Density (gas) & $1.185 \mathrm{~kg} / \mathrm{m}^{3}$ \\
& Dynamic viscosity & $1.831 \cdot 10^{-5} \mathrm{~kg} /(\mathrm{m} \mathrm{s})$ \\
& Thermal conductivity & $2.61 \cdot 10^{-2} \mathrm{~W} /(\mathrm{m} \mathrm{K})$ \\
& Specific heat capacity & $1004.4 \mathrm{~J} /(\mathrm{kg} \mathrm{K})$ \\
\hline
\end{tabular}


Table 3 Material properties for Schulamid 66 SK 1000, a very high impact modified polyamide 66

\begin{tabular}{lll}
\hline Property & Unit & Value (dry/condensed) \\
\hline Young's modulus & $\mathrm{MPa}$ & $1800 / 600$ \\
Tensile yield stress & $\mathrm{MPa}$ & $50 / 30$ \\
Tensile elongation & $\%$ & $6 / 32$ \\
Charpy impact strength $\left(23{ }^{\circ} \mathrm{C}\right)$ & $\mathrm{kJ} / \mathrm{m}^{2}$ & $80 / 120$ \\
Vicat softening temperature & ${ }^{\circ} \mathrm{C}$ & 175 \\
$\left(50{ }^{\circ} \mathrm{C} / \mathrm{h}, 50 \mathrm{~N}\right)$ & & \\
Melt temperature & ${ }^{\circ} \mathrm{C}$ & $280-300$ \\
Mold temperature & ${ }^{\circ} \mathrm{C}$ & $60-100$ \\
Moisture absorption & $\%$ & 2 \\
Density (solid) & $\mathrm{kg} / \mathrm{m}^{3}$ & 1060 \\
Predrying time & $\mathrm{h}$ & $4-6$ \\
Predrying temperature & ${ }^{\circ} \mathrm{C}$ & 80 \\
\hline
\end{tabular}

Due to the filling pressure the melt column is compressed between the screw tip and the flow front. This column decompresses when the changeover point is reached and the injection is stopped. Accordingly, the size of this column affects the degree of filling achieved. Since the compressibility is not represented or considered in the simulation, the column should be kept constant. This allows comparability of the filling simulation with the experimental results. For this purpose, the filling series was performed by changing the metering volume instead of varying the changeover point. In this way, the influence of the compressible melt column is kept constant over the filling levels and is not considered further in this study. The other setting parameters were kept at their previously determined values. It should also be

Table 4 Setting and process data of the injection molding process (Engel EM 200/100)

\begin{tabular}{lll}
\hline Property & Unit & Value \\
\hline Clamping force & $\mathrm{kN}$ & 500 \\
Mold temperature (inlet flow) & ${ }^{\circ} \mathrm{C}$ & 80 \\
Cylinder temp. zone 1 (nozzle) & ${ }^{\circ} \mathrm{C}$ & 275 \\
Cylinder temp. zone 2 & ${ }^{\circ} \mathrm{C}$ & 280 \\
Cylinder temp. zone 3 & ${ }^{\circ} \mathrm{C}$ & 265 \\
Cylinder temp. zone 4 & ${ }^{\circ} \mathrm{C}$ & 255 \\
Cylinder temp. zone 5 (feeding) & ${ }^{\circ} \mathrm{C}$ & 40 \\
Injection speed & $\mathrm{cm}^{3} / \mathrm{s}$ & 37.2 \\
Metering volume & $\mathrm{cm}^{3}$ & variable \\
Metering speed & $\mathrm{m} / \mathrm{s}$ & 0.4 \\
Back pressure & $\mathrm{bar}^{2}$ & 50 \\
Residual cooling time & $\mathrm{S}$ & 15 \\
Melt cushion & $\mathrm{cm}^{3}$ & const. \\
Changeover point holding pressure & $\mathrm{cm}^{3}$ & const. \\
Shut-off nozzle (yes/no) & - & yes \\
\hline
\end{tabular}

mentioned that 10 cycles of each setting were initially carried out to achieve a steady-state on the machine and mold.

After the filling study has been carried out, the molded parts to be investigated were digitized for comparison with the simulation results. For this purpose, the molded parts were placed in the mold insert and photographed. For this, the mold was first oriented with the cavity pointing upwards (Fig. 6). The camera was fixed above the mold insert to ensure the same perspective for all images. The point-shaped tunnel sprue ensured precise insertion of the molded parts into the mold cavity.

After the filling levels have been recorded, the images were first processed and scaled. This correction was necessary because the parts are subject to the generally known (post-) shrinkage. In our case, the volumetric homogeneous shrinkage was $1.95 \%$. The shrunken parts then no longer have the dimensions that would represent the actual fill level in the mold. Accordingly, the complete filled part was first used, and this was scaled in the image processing in length and width until it completely filled the cavity. The scaling factors obtained in this way were then applied to the other filling stages (images).

\section{Comparison of simulation results and experimental observations}

In order to provide a sound comparison of the simulations results with the experimental observations from the injection molding machine, the temporal evolution of the mold filling is presented visually in a first step, cf. Fig. 7. The experimental mold filling is displayed on the left, and the simulation of the mold filling with the different viscosity models

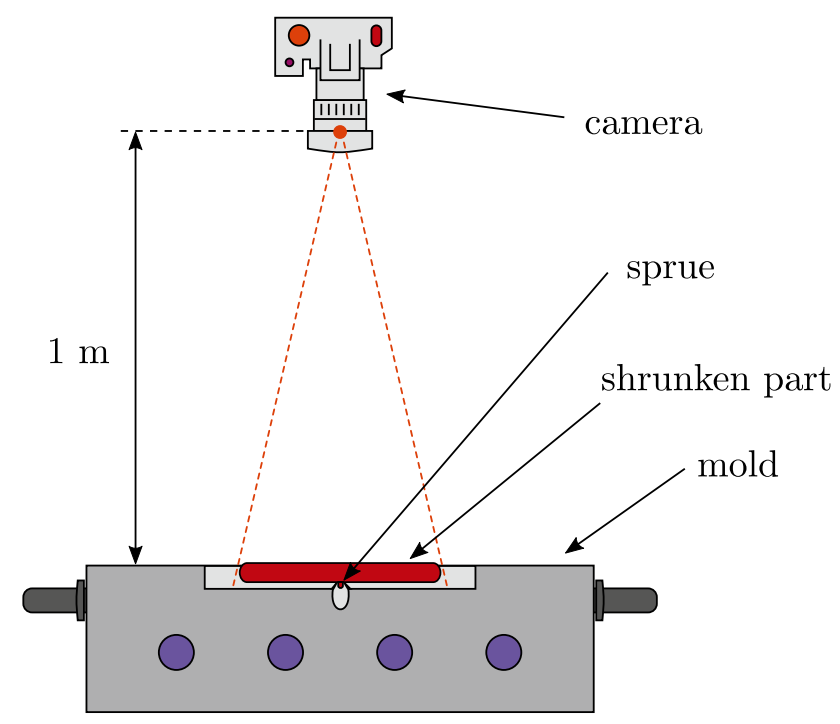

Fig. 6 Setup for the digitization of the molded parts 


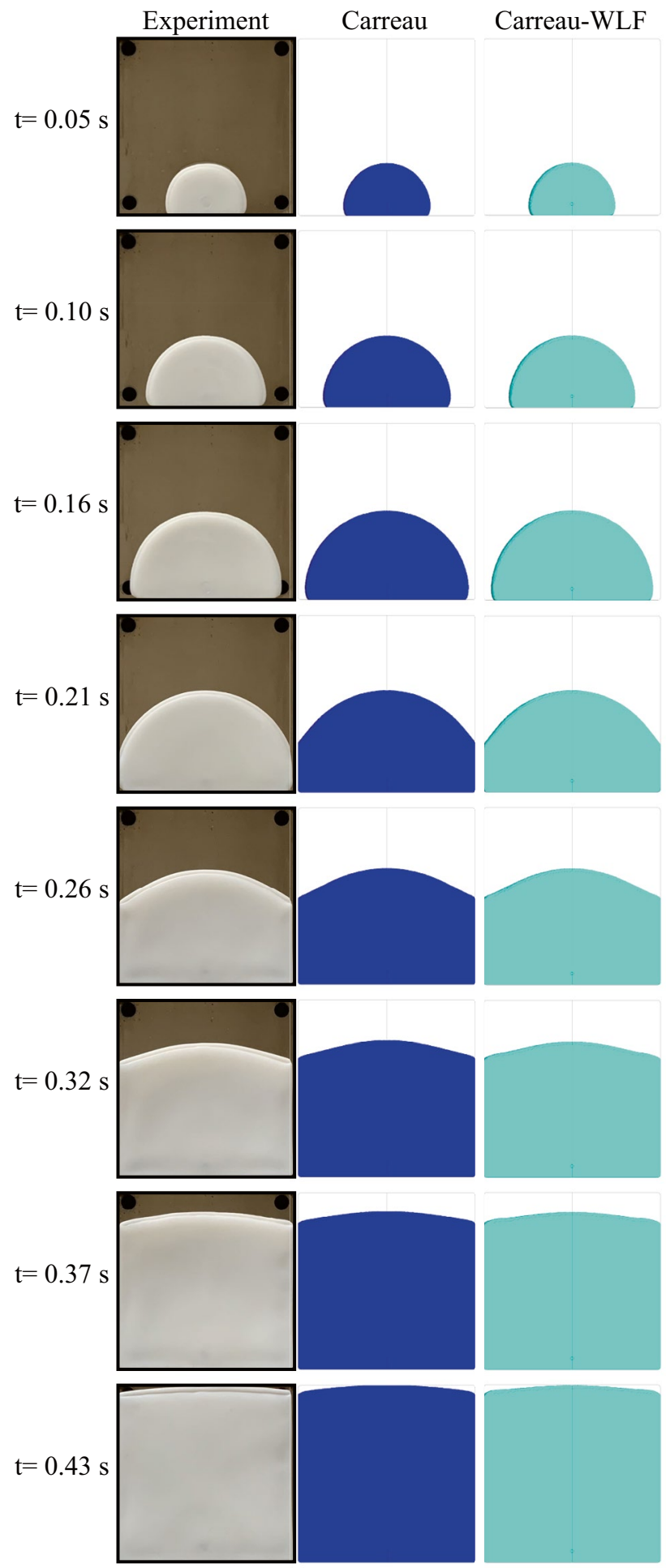

Fig. 7 Comparison of the mold filling between the experiments and the simulation with different viscosity models at different time steps

are shown on the right side of the figure. This qualitative comparison provides different stages of the mold filling at the pre-defined time steps $0.05 \mathrm{~s}, 0.1 \mathrm{~s}, 0.16 \mathrm{~s}, 0.21 \mathrm{~s}, 0.26 \mathrm{~s}$,
$0.32 \mathrm{~s}, 0.37 \mathrm{~s}$ and $0.43 \mathrm{~s}$. Figure 7 shows a good agreement between simulation and experiment.

For a more precise quantitative comparison, the coordinates of the points characterizing the flow front in the midplane of the volume are extracted from Ansys CFX, cf. Fig. 8. Due to the parabolic shape of the flow front in the thickness direction, the outermost area of the flow front can be used within the midplane.

The aforementioned points can be output as two-dimensional coordinates and connected by a polyline. For the transfer of the experimental flow front data into a two-dimensional coordinate system, the method described in Chapter 4 is used for digitization. To calculate the respective point data from the digitized images and provide it for the given two-dimensional coordinate system, the data extraction software Digizelt is employed. This software is used to transfer graphical information into digital information (in form of coordinate points) [53, 54]. The extracted values plotted in Fig. 8 illustrate the relatively accurate representation of experimental results by the simulated flow front. Especially in the middle area of the flow front, the parabolic expression of the flow front is very accurate. Only at the edge regions of the early filling stage minor differences between experiment and simulation are evident. These inaccuracies disappear in the later filling process. It is apparent that the real polymer flow in the mold is not perfectly symmetric due to slight asymmetries in the mold temperature distribution, the surface roughness and manufacturing tolerances. By comparing the simulation of the viscosity models with the experiments, it can be seen that the two flow fronts of the Carreau and Carreau-WLF models hardly differ in the early filling phase. In the further filling phases, it can be seen that the flow front of the Carreau model slightly separates and rushes ahead. On the other hand, the Carreau-WLF model reproduces the experimental results better, especially in the middle part of the flow front.

Figure 9 shows the temperature profile in the respective midplane of the top view and side view. These temperature profiles are shown at different time steps. The temperature field observed in the early filling phase is very similar for both viscosity models. Later on, the Carreau-WLF model shows increased temperature values mainly at the flow front due to internal fluid friction. In the Carreau model, lower temperature values evolve throughout the filled geometry as a result of the missing heat from shear-induced heating like in the Carreau-WLF model.

Figure 10 shows the viscosity profiles of both models at different time steps. There, a similar viscosity distribution is formed at the beginning. In the later progress, the flow in the Carreau-WLF framework obviously has to overcome higher viscosity than in the simple Carreau model. Especially in the edge region of the side view, one can see a significantly lower viscosity in the Carreau model over the entire course of time. From the time step $0.21 \mathrm{~s}$, the typical flow behavior of the fountain flow is formed in the Carreau-WLF model, 
Fig. 8 Comparison of the flow front (midplane) between the simulation and experiments at different time steps

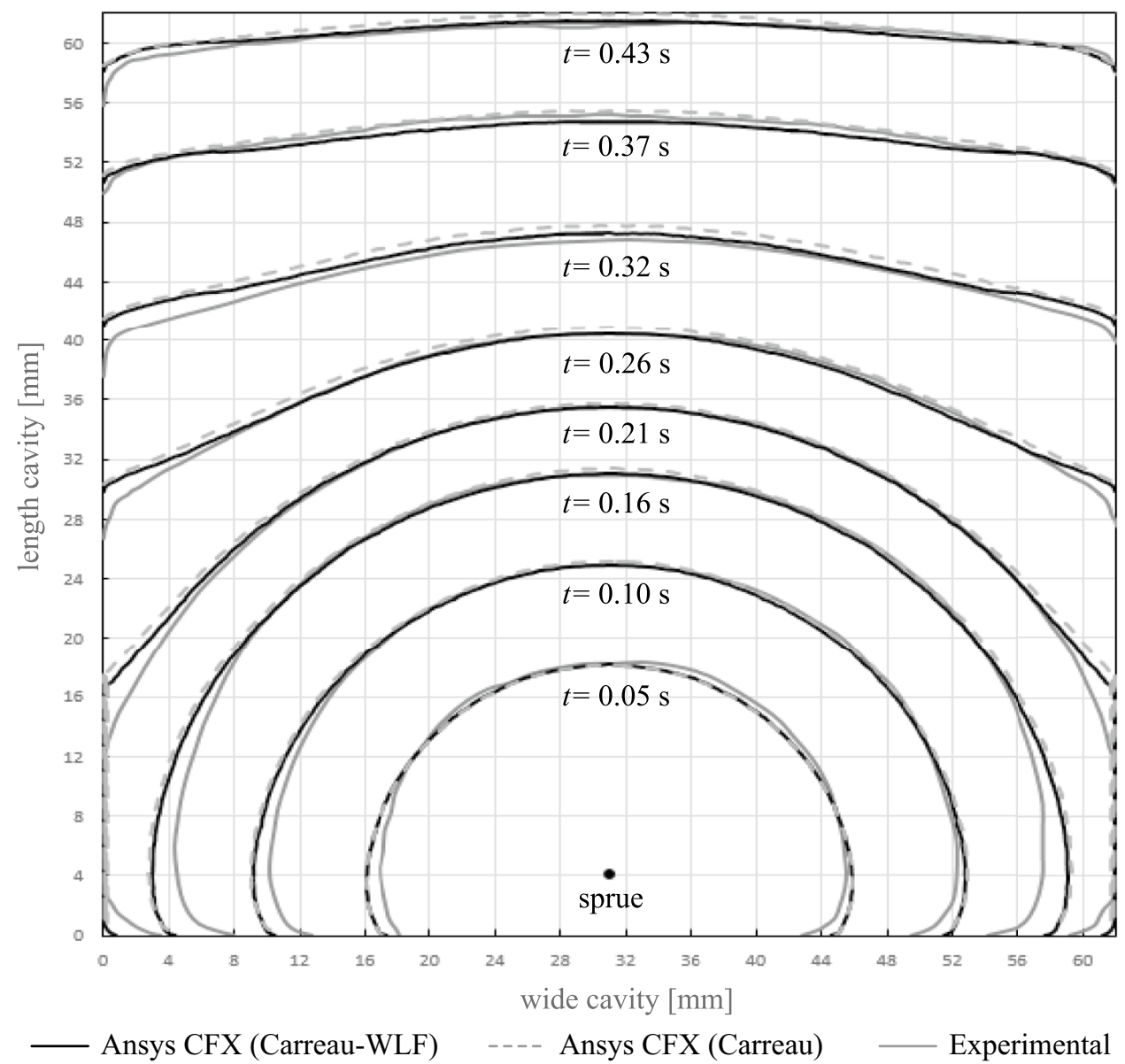

with the cooling of the melt in the wall region. This cooling mechanism can also be seen in the view of the center plane in the advanced filling. The viscosity is very high in the lower corners close to the sprue. Compared with the Carreau model, a relatively homogeneous viscosity distribution can be seen over all time steps. This relatively homogeneous viscosity distribution can be explained by the assumption of constant temperature in the viscosity model. Only the shear rate has an influence on the viscosity in the Carreau model. Whereas in the Carreau-WLF model, the temperature influence is taken into account by the temperature shift factor. Both models can only show an identical viscosity if $T=T_{0}=290^{\circ} \mathrm{C}$ and thus $\alpha_{T}=0$. Due to the different viscosity distributions of the two models, the advance of the melt front can be explained by Fig. 8 .

In the last step, the filling levels of the experiment and simulation are compared. Ansys CFX uses a filling level calculation described in Eq. 13.

$F L_{\text {simulation }}=\frac{V_{\text {vol. frac. }}}{V_{\text {cavity }}} \cdot 100 \%$

This equation includes a volumetric filling level from the simulation $F L_{\text {simulation }}$, the volume fraction of the melt
$V_{\text {vol. frac. }}$ and the volume of the cavity $V_{\text {cavity }}$. The calculations are performed automatically in Ansys CFX post-processing. The results are assigned to the respective time steps of the simulation and the experiments, cf. Table 5.

The filling levels of the experiments are determined on the basis of a mass ratio. As shown in Eq. 14, the respective mass of the current specimen is considered relative to the fully filled molded part.

$F L_{\text {experiments }}=\frac{m_{\text {part }}}{m_{\text {fully filled part }}} \cdot 100 \%$

Here $F L_{\text {experiments }}$ is the filling level of the experiments, $m_{\text {part }}$ is the mass of the part and $m_{\text {fully filled part }}$ is the mass of the fully filled reference part, produced without holding pressure. For the calculation of the mass of the experiments, the arithmetic mean of five molded parts is taken into account. This arithmetic average of the mass $m_{\text {part }}$ is listed in Table 5 and serves as a reference for the calculation of the filling level. A fully filled molded part has a mass of $m_{\text {fully filled part }}=7.65 \mathrm{~g}$. Please note that in our setup the filling levels $F L_{\text {simulation }}$ and $F L_{\text {experiments }}$ are equivalent, thins the packing phase after the mold filling is omitted. The mass of the molded parts was determined by using the 


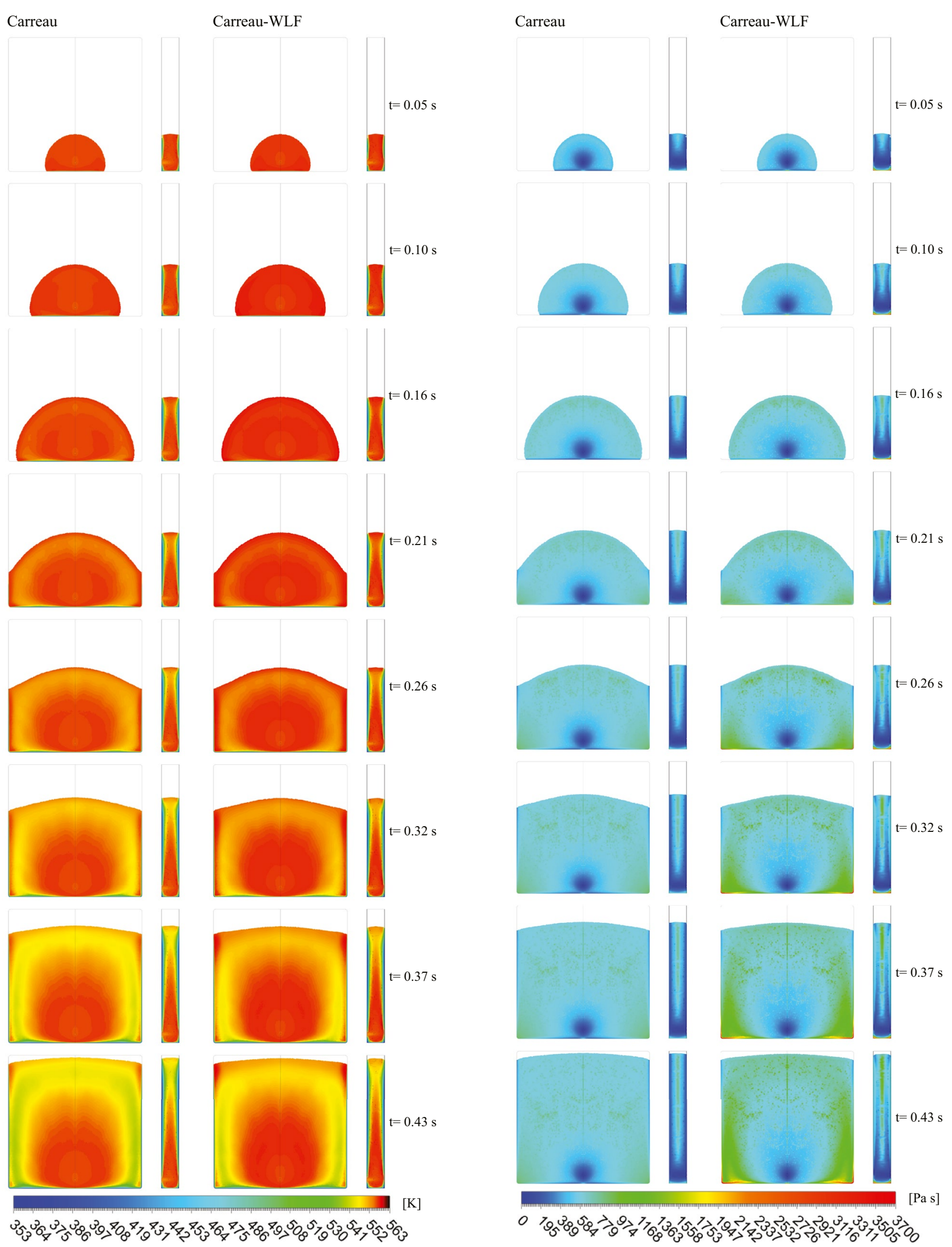

Fig. 9 Comparison of the temperature profile (midplane of top view and side view) between the Carreau model and the Carreau-WLF model at different time steps

Fig. 10 Comparison of the viscosity profile (midplane of top view and side view) between the Carreau model and the Carreau-WLF model at different time steps 
Table 5 Filling level of the experimental and simulation results

\begin{tabular}{llllll}
\hline Time step & Dosing & $\begin{array}{l}\text { Average part } \\
\text { mass }\end{array}$ & $\begin{array}{l}\text { Filling level } \\
\text { (experiment) }\end{array}$ & \multicolumn{2}{l}{ Filling level (simulation) } \\
\cline { 5 - 6 } & & & & Carreau & Carreau-WLF \\
\hline $0.05 \mathrm{~s}$ & $7.30 \mathrm{~cm}^{3}$ & $0.83 \mathrm{~g}$ & $10.85 \%$ & $11.39 \%$ & $11.34 \%$ \\
$0.10 \mathrm{~s}$ & $9.30 \mathrm{~cm}^{3}$ & $1.66 \mathrm{~g}$ & $21.69 \%$ & $22.80 \%$ & $22.68 \%$ \\
$0.16 \mathrm{~s}$ & $11.30 \mathrm{~cm}^{3}$ & $2.66 \mathrm{~g}$ & $34.76 \%$ & $36.48 \%$ & $36.29 \%$ \\
$0.21 \mathrm{~s}$ & $13.30 \mathrm{~cm}^{3}$ & $3.53 \mathrm{~g}$ & $46.13 \%$ & $47.86 \%$ & $47.59 \%$ \\
$0.26 \mathrm{~s}$ & $15.30 \mathrm{~cm}^{3}$ & $4.34 \mathrm{~g}$ & $56.71 \%$ & $59.23 \%$ & $58.89 \%$ \\
$0.32 \mathrm{~s}$ & $17.30 \mathrm{~cm}^{3}$ & $5.42 \mathrm{~g}$ & $70.82 \%$ & $72.98 \%$ & $72.55 \%$ \\
$0.37 \mathrm{~s}$ & $19.30 \mathrm{~cm}^{3}$ & $6.40 \mathrm{~g}$ & $83.63 \%$ & $84.46 \%$ & $83.97 \%$ \\
$0.43 \mathrm{~s}$ & $21.30 \mathrm{~cm}^{3}$ & $7.29 \mathrm{~g}$ & $95.26 \%$ & $98.20 \%$ & $97.68 \%$ \\
\hline
\end{tabular}

high-precision scale Kern \& Sohn EWJ 300-3. The results in Table 5 show that the filling levels are very close to each other. The figures of the melt fronts already give an idea of this difference. In these figures, it is easy to see that the edge region, in particular, was not so clearly pronounced in the experiments leading to a slight deviations of the filling levels in Table 5. A reason for the locally retarded polymer flow in the experiments maybe found in the contact mechanism between the polymer melt and the mold wall. In the results of the filling level, a clear tendency of the different viscosity models can be observed. Since higher viscosity is associated with greater flow resistance, the Carreau-WLF model produces a slightly slower filling than the simple Carreau model. This is also the reason for the better agreement to the experimental results. For filling larger product volumes and more complex geometries the deviation between the results for Carreau and Carreau-WLF model will become more pronounced.

\section{Conclusion and outlook}

The provided study shows how numerical approximation of the injection molding filling process can be conducted with Ansys CFX. The framework of Ansys CFX is suitable for the wall thickness of typical injection molded parts. The experimental and numerical results are almost equivalent in terms of flow front evolution and the filling levels. Only in the boundary regions of the midplane between the polymer and the wall region minor differences are present. These may be due to the slightly worn surface in the edge region of the injection mold. The worn surface can cause increased shear stresses, which has a negative effect on melt spreading. Likewise, the neglected surface tension in the simulation can lead to an additional inaccuracy in the flow front expression [55]. The minor deviations in the mass can be explained by the slight experimental inaccuracy of the screw movement in the injection molding process.
Since the differences between the experiments and the simulation are relatively small, it can be assumed that the filling process can be approximated very well with the Carreau-WLF viscosity model by the Ansys CFX software.

The contribution also illustrates the effect of shearinduced temperature changes and the interplay between the temperature field and the viscosity of the injected polymer in the Carreau-WLF framework. By a comparison to the simple Carreau model, the influence of the choice of viscosity model on the evolution of the flow front and the filling level is presented.

Acknowledgements This contribution has been developed in the project OptiTemp. The research project OptiTemp (reference number 13FH012PX8) is partly funded by the German Federal Ministry of Education and Research (BMBF) within the research program FHprofUnt 2018.

Author contributions All authors contributed to the design and implementation of the research, to the analysis of the results and to the writing of the manuscript.

Funding Open Access funding enabled and organized by Projekt DEAL. The research leading to these results received funding from German Federal Ministry of Education and Research (BMBF) under Grant Agreement No 13FH012PX8.

Availability of data and material Not applicable.

Code availability Not applicable.

\section{Declarations}

Ethics approval Not applicable.

Consent to participate The authors claim that none of the contents in this manuscript has been published or considered for publication elsewhere.

Consent for publication All authors have checked the manuscript and have agreed to the submission.

Competing interests The authors declare no competing interests. 
Open Access This article is licensed under a Creative Commons Attribution 4.0 International License, which permits use, sharing, adaptation, distribution and reproduction in any medium or format, as long as you give appropriate credit to the original author(s) and the source, provide a link to the Creative Commons licence, and indicate if changes were made. The images or other third party material in this article are included in the article's Creative Commons licence, unless indicated otherwise in a credit line to the material. If material is not included in the article's Creative Commons licence and your intended use is not permitted by statutory regulation or exceeds the permitted use, you will need to obtain permission directly from the copyright holder. To view a copy of this licence, visit http://creativecommons.org/licenses/by/4.0/.

\section{References}

1. Han SY, Kwag JK, Kim CJ, Park TW, Jeong YD (2004) A new process of gas-assisted injection molding for faster cooling. $\mathrm{J}$ Mater Process Technol 155-156:1201-1206. https://doi.org/10. 1016/j.jmatprotec.2004.04.338

2. Holm EJ, Langtangen HP (1999) A unified finite element model for the injection molding process. Comput Methods Appl Mech Eng 178(3-4):413-429

3. Kietzmann CVL, Van Der Walt JP, Morsi YS (1998) A freefront tracking algorithm for a control-volume-based Hele-Shaw method. Int J Numer Methods Eng 41(2):253-269. https://doi.org/ 10.1002/(SICI)1097-0207(19980130)41:2<253::AID-NME282> 3.0.CO; $2-7$

4. Hele-Shaw HS (1899) The motion of a perfect liquid. Proceedings of the Royal Institution of Great Britain 16:49-64

5. Tadmor Z, Broyer E, Gutfinger C (1974) Flow analysis network (fan)-a method for solving flow problems in polymer processing. Polym Eng Sci 14(9):660-665

6. Hieber CA, Shen SF (1980) A finite-element-finite-difference simulation of the injectionmolding filling process. J Non-Newtonian Fluid Mech 7:1-32

7. Wang J, Silva C, Viana J, van Hattum F, Cunha A, Tucker C (2008) Prediction of fiber orientation in a rotating compressing and expanding mold. Polym Eng Sci 48(7):1405-1413

8. Chiang HH, Hieber CA, Wang KK (1991) A unified simulation of the filling and postfilling stages in injection molding. Part I: Formulation. Polym Eng Sci 31(2):116-124

9. Chen BS, Liu WH (1994) Numerical simulation of the post-filling stage in injection molding with a two-phase model. Polym Eng Sci 34(10):835-846

10. Han KH, Im YT (1997) Compressible flow analysis of filling and postfilling in injection molding with phase-change effect. Compos Struct 38(1-4):179-190

11. Himasekhar K, Lottey J, Wang KK (1992) CAE of mold cooling in injection molding using a three-dimensional numerical simulation. J Eng Ind 114(2):213-221

12. Jeffery GB (1922) The motion of ellipsoidal particles immersed in a viscous fluid. Proceedings of the Royal Society of London. Series A, Containing Papers of a Mathematical and Physical Character 102:161-179

13. Folgar F, Tucker CL (1984) Orientation behavior of fibers in concentrated suspensions. J Reinf Plast Compos 3(2):98-119

14. Chung ST, Kwon TH (1996) Coupled analysis of injection molding filling and fiber orientation, including in-plane velocity gradient effect. Polym Compos 17(6):859-872

15. Wang J, O'Gara JF, Tucker CL (2008) An objective model for slow orientation kinetics in concentrated fiber suspensions: Theory and rheological evidence. J Rheol 52:1179-1200
16. Pantani R, Titomanlio G (1999) Analysis of shrinkage development of injection moulded ps samples. Int Polym Process 14(2):183-190

17. Pontes AJ, Pantani R, Titomanlio G, Pouzada AS (2000) Solidification criterion on shrinkage predictions for semi-crystalline injection moulded samples. Int Polym Process 15(3):284-290

18. Chiang HH, Himasekhar K, Santhanam N, Wang KK (1993) Integrated simulation of fluid flow and heat transfer in injection molding for the prediction of shrinkage and warpage. J Eng Mater Technol 115(1):37-47

19. Kabanemi KK, Crochet MJ (1992) Thermoviscoelastic calculation of residual stresses and residual shapes of injection molded parts. Int Polym Process 7(1):60-70

20. Zheng R, Kennedy P, Phan-Thien N, Fan XJ (1999) Thermoviscoelastic simulation of thermally and pressure-induced stresses in injection moulding for the prediction of shrinkage and warpage for fibre-reinforced thermoplastics. J Non-Newtonian Fluid Mech 84(2-3):159-190

21. Choi DS, Im YT (1999) Prediction of shrinkage and warpage in consideration of residual stress in integrated simulation of injection molding. Compos Struct 47(1-4):655-665

22. Kabanemi KK, Vaillancourt H, Wang H, Salloum G (1998) Residual stresses, shrinkage, and warpage of complex injection molded products: Numerical simulation and experimental validation. Polym Eng Sci 38(1):21-37

23. Hassan H, Regnier N, Le Bot C, Defaye G (2010) 3D study of cooling system effect on the heat transfer during polymer injection molding. Int J Therm Sci 49(1):161-169

24. Hétu JF, Gao DM, Garcia-Rejon A, Salloum G (1998) 3D finite element method for the simulation of the filling stage in injection molding. Polym Eng Sci 38(2):223-236

25. Pichelin E, Coupez T (1998) Finite element solution of the 3D mold filling problem for viscous incompressible fluid. Comput Methods Appl Mech Eng 163(1-4):359-371

26. Pichelin E, Coupez T (1999) A Taylor discontinuous Galerkin method for the thermal solution in 3D mold filling. Comput Methods Appl Mech Eng 178(1-2):153-169

27. Chang RY, Yang WH (2001) Numerical simulation of mold filling in injection molding using a three-dimensional finite volume approach. Int J Numer Methods Fluids 37(2):125-148

28. Khayat RE, Plaskos C, Genouvrier D (2001) An adaptive boundary-element approach for 3D transient free surface cavity flow, as applied to polymer processing. Int J Numer Methods Eng 50(6):1347-1368

29. Anders D, Baum M, Alken J (2021) A comparative study of numerical simulation strategies in injection molding. 14th WCCM-ECCOMAS Congress 2020. https://doi.org/10.23967/ wccm-eccomas.2020.005

30. Spina R (2006) Optimisation of injection moulded parts by using ANN-PSO approach. Journal of Achievements in Materials and Manufacturing Engineering 15:46-52

31. Kurtaran H, Ozcelik B, Erzurumlu T (2005) Warpage optimization of a bus ceiling lamp base using neural network model and genetic algorithm. J Mater Process Technol 169(2):314-319. https://doi.org/10.1016/J.JMATPROTEC.2005.03.013

32. Shen C, Wang L, Li Q (2007) Optimization of injection molding process parameters using combination of artificial neural network and genetic algorithm method. J Mater Process Technol 183(23):412-418. https://doi.org/10.1016/J.JMATPROTEC.2006.10. 036

33. Ozcelik B, Erzurumlu T (2006) Comparison of the warpage optimization in the plastic injection molding using Anova, neural network model and genetic algorithm. J Mater Process Technol 171(3):437-445. https://doi.org/10.1016/J.JMATPROTEC.2005. 04.120 
34. Ding Y, Hassan MH, Bakker O, Hinduja S, Bártolo P (2021) A review on microcellular injection moulding. Materials 14(15). https://doi.org/10.3390/ma14154209

35. Zhou H (2013) Computer modeling for injection molding: simulation, optimization, and control. Wiley

36. Bociaga E, Jaruga T (2006) Visualization of melt flow lines in injection moulding. Journal of Achievements of Materials and Manufacturing Engineering 331-334

37. Mukras SMS, Al-Mufadi FA (2016) Simulation of HDPE mold filling in the injection molding process with comparison to experiments. Arab J Sci Eng 41(5):1847-1856. https://doi.org/10.1007/ s13369-015-1970-9

38. Rusdi MS, Abdullah MZ, Mahmud AS, Khor CY, Abdul Aziz MS, Abdullah MK, Yusoff H, Firdaus SM (2015) Numerical investigation on the effect of injection pressure on melt front pressure and velocity drop. Appl Mech Mater 786:210-214. https://doi.org/10. 4028/www.scientific.net/AMM.786.210

39. Igreja R (2007) Numerical simulation of the filling and curing stages in reaction injection moulding, using CFX. Ph.D. thesis, Universidade de Aveiro. https://doi.org/10.13140/2.1.3782.7523

40. Haagh GAAV, van de Vosse FN (1998) Simulation of threedimensional polymer mould filling processes using a pseudoconcentration method. Int J Numer Methods Fluids 28(9):13551369. https://doi.org/10.1002/(SICI)1097-0363(19981215)28:9< 1355::AID-FLD770>3.0.CO;2-C

41. Haagh GAAV, Peters GWM, van de Vosse FN, Meijer HEH (2001) A 3-d finite element model for gas-assisted injection molding: simulations and experiments. Polym Eng Sci 41(3):449-465. https://doi.org/10.1002/pen.10742

42. Frank $T$ (2005) Advances in computational fluid dynamics (CFD) of 3-dimensional gasliquid multiphase flows. NAFEMS Seminar: Simulation of Complex Flows (CFD) - Applications and Trends. pp 1-18

43. Carreau PJ (1968) Rheological equations from molecular network theories. Ph.D. thesis, University of Wisconsin

44. Geiger K, Khnle H (1984) Analytische berechnung einfacher scherströmungen aufgrund eines fliegesetzes vom Carreauschen typ. Rheol Acta 23(4):355-367. https://doi.org/10. 1007/BF01329188

45. Hieber CA, Chiang HH (1992) Shear-rate-dependence modeling of polymer melt viscosity. Polym Eng Sci 32(14):931-938. https:// doi.org/10.1002/pen.760321404

46. Williams ML, Landel RF, Ferry JD (1955) The temperature dependence of relaxation mechanisms in amorphous polymers and other glass-forming liquids. J Am Chem Soc 77(14):3701-3707. https://doi.org/10.1021/ja01619a008

47. Karrenberg G, Neubrech B, Wortberg J (2016) CFD-simulation der kunststoffplastifizierung in einem extruder mit durchgehend genutetem zylinder und barriereschnecke. Zeitschrift Kunststofftechnik / Journal of Plastics Technology 12(3):205-238. https:// doi.org/10.3139/O999.04032016

48. O'Connell PA, McKenna GB (1999) Arrhenius-type temperature dependence of the segmental relaxation below tg. J Chem Phys 110(22):11054-11060. https://doi.org/10.1063/1.479046

49. Plazek DJ, Ngai KL (1991) Correlation of polymer segmental chain dynamics with temperature-dependent time-scale shifts. Macromolecules 24(5):1222-1224. https://doi.org/10.1021/ma00005a044

50. Rowland HD, King WP, Sun AC, Schunk PR, Cross Graham LW (2007) Predicting polymer flow during high-temperature atomic force microscope nanoindentation. Macromolecules 40(22):80968103. https://doi.org/10.1021/ma0704358

51. Fernandez A, Muniesa M, Javierre C (2014) In-line rheological testing of thermoplastics and a monitored device for an injection moulding machine: Application to raw and recycled polypropylene. Polym Test 33:107-115. https://doi.org/10.1016/j.polymertesting. 2013.11.008

52. Baum M, Anders D (2021) A numerical simulation study of mold filling in the injection molding process. Computer Methods in Materials Science 21(1):25-34. https://doi.org/10.7494/cmms. 2021.1.0743

53. Phan K, Tian DH, Cao C, Black D, Yan TD (2005) Systematic review and meta-analysis: techniques and a guide for the academic surgeon. Annals of Cardiothoracic Surgery 4(2):112-122. https:// doi.org/10.3978/j.issn.2225-319X.2015.02.04

54. Atkinson G (2014) Shear rate normalization is not essential for removing the dependency of flow-mediated dilation on baseline artery diameter: past research revisited. Physiol Meas 35(9):18251835. https://doi.org/10.1088/0967-3334/35/9/1825

55. Wang W, Li X, Han X (2012) Numerical simulation and experimental verification of the filling stage in injection molding. Polym Eng Sci 52(1):42-51. https://doi.org/10.1002/PEN.22043

Publisher's Note Springer Nature remains neutral with regard to jurisdictional claims in published maps and institutional affiliations. 